\title{
PHYTOPLANKTON AND ZOOPLANKTON MODELING IN THE CHAHNIMEH MAN-MADE RESERVOIR BY MEANS OF ISSADM
}

\author{
HASHEMI MONFARED, S.A. - MiRBAGHERI, S.A. - SADRNEJAD, S.A. \\ Civil Engineering Faculty, K. N. Toosi University of Technology, Tehran, Iran \\ (phone: +98-21-88779623, fax: +98-21-88779476) \\ *Corresponding author \\ e-mail:a_hashemi_m@dena.kntu.ac.ir \\ (Received 26 $6^{\text {th }}$ March 2011; accepted $7^{\text {th }}$ February 2013)
}

\begin{abstract}
The increase of phytoplankton and zooplankton in the lakes and reservoirs that supply water to downstream regions is an important environmental issue. In this paper, concentrations of phytoplankton and zooplankton in Chahnimeh reservoir are predicted using an Integrated Seasonal Separate AdvectionDiffusion Model (ISSADM). Chahnimeh reservoir is a seminatural deep hole that is stagnant in some part of the reservoir for most of the year. ISSADM is a three-dimensional numerical model based on a finitevolume solution that was developed to predict water quality in lakes and reservoirs affected by seasonal rivers. The model is capable of simulating water-quality parameters, as well as phytoplankton and zooplankton concentrations. To verify the model, field measurements and experiments conducted during a one-year period were compared with model results, demonstrating good agreement. The model is appropriate for predicting phytoplankton and zooplankton concentrations as well as eutrophication processes in similar, seasonal, aquatic environments.
\end{abstract}

Keywords: modeling, phytoplankton, zooplankton, reservoir, Chahnimeh

\section{Introduction}

Many lakes and reservoirs are frequently attacked by the pollutants dissolved in water flows near agricultural lands and industrial zones. Therefore, it is essential to estimate the concentrations of various ions, compounds, plants and aquatic organisms in water bodies to control their levels. The concentrations of additives and chemical substances, such as nitrogen and phosphorous compounds, are elevated in the reservoir because they are used on most agricultural lands and are available in industrial wastewater. Nitrogen, phosphorous and solar radiation are the main factors controlling phytoplankton growth; in certain cases, the main source of food for zooplankton is phytoplankton. Therefore, to predict and control water quality in a reservoir, the concentrations of phytoplankton and zooplankton should be calculated continuously. In this paper, predicted concentrations consider surface algae to be members of the phytoplankton group, and small fishes are excluded from the zooplankton population prediction.

The concentrations of phytoplankton and zooplankton in aquatic environments have been studied by many researchers in recent years. Veraszto et al. (2010) studied on long-term dynamic patterns and diversity of phytoplankton communities in a large eutrophic river. The seasonal variations in the sediment biogenic properties of a tropical mangrove environment in southwest coast of India were studied by Neil et al. (2009). Hydrochemistry of Lakes of the Patagonian Province of Tierra del Fuego was investigated by Conzonno and Ulibarrena (2009). Identification of temporal and spatial variations of water quality in Sanya Bay, China by three-way principal component analysis was done by De Dong et al. (2009). The analysis method and modeling in these 
researches were most statistical. Hamilton et al. (2008) studied the patchiness and role of phytoplankton in a stratified lake using three- and one-dimensional predictive models, where results were compared with field data. Mieleitner and Reichert (2008) modeled the functional groups of phytoplankton in three lakes. They categorized phytoplankton into different groups and compared the results of the BELAMO model with field data. Kuo et al. (2008) used dynamic programming in a model for eutrophication management in Taiwan, and Burger et al. (2008) modeled the relative importance of nutrient loads and phytoplankton biomass in a shallow lake. To estimate the effect of nutrients and grazing zooplankton on phytoplankton, Malve et al. (2007) applied a Bayesian model for algal mass within a lake water-quality model. Elliott et al. (2007) used a phytoplankton community model and a lake physical model to simulate the phytoplankton community of Lake Erke, Sweden. Phosphorus cycle dynamics and algal growth in a reservoir were modeled by Komatsu et al. (2006). Their model considers vertical and longitudinal concentration variations in a narrow lake. Skliris and Djenidi (2008) studied plankton dynamics near a submarine by a hydrodynamic process. They used a three-dimensional numerical model coupled with a coastal plankton ecosystem model to estimate the impact of the hydrodynamic process on the evolution of the spring phytoplankton bloom. A numerical model for the role of zooplankton in nutrient cycling was developed by Bruce et al. (2006), who used coupled hydrodynamic and ecological models and an extensive field data set to simulate these processes. Edwards et al. (2005) investigated the impact of a benthic filter on the transport of algae to the benthos. Their main objective was to calculate the benthic consumption of algae in lakes. Trancoso et al. (2005) modeled macro algae in an estuary with a three-dimensional hydrodynamic-ecological model, MOHID. They simulated the atmosphere, nutrient levels and sediment hydrodynamics of a coastal lagoon. Jiao et al. (2004) investigated a statistical model that mathematically linked Chlorophyl-a concentration to seven environmental factors. Their model applied linear stepwise regression to data from a two-year period in order to identify factors with significant effects on algal concentration. Phytoplankton in shallow and deep lakes were simulated using PROTECH by Elliott and Thackeray (2004), who integrated a plankton community model and planktonic responses to environmental change into a new version of the model for a shallow lake. Rukhovets et al. (2003) developed a new model to simulate phytoplankton succession during eutrophication, and their modeling results corresponded adequately to the field data. Thi et al. (2003) investigated threedimensional phytoplankton dynamics in a light-limited environment with modeling analysis and simulation. Bonnet and Poulin (2002) developed a numerical model for planktonic succession in a nutrient-rich reservoir by applying a-one dimensional numerical model to study of the effects of light on important factors controlling cyanobacterial growth. Remote sensing was coupled with a computational fluid dynamic model by Hedger et al. (2002). They predicted the Chl-a concentrations in a shallow meso-eutrophic lake based on surface images from remote sensing. Lewis et al. (2002) used PROTECH, a freshwater phytoplankton model, to simulate an artificially stratified reservoir. Asaeda et al. (2001) modeled macrophyte-nutrient-phytoplankton interactions in shallow lakes. Their numerical model incorporates phytoplankton and submerged macrophytes to simulate concentrations at different times. Walter et al. (2001) used an ANN model to predict SALMO and eutrophication processes in reservoirs, and similar studies were done by Krivtsov et al. (2001) and Xu et al. (1999). Algal growth in warm-temperature reservoirs was also investigated by Sterner et al. 
(1998), who considered the effects of nitrogen, temperature, light and other nutrients to predict algal growth in natural environments. Most of the models mentioned here are two-dimensional or consider only the source/sink effects of phytoplankton and zooplankton.

\section{Materials and methods}

\section{Model formulation}

ISSADM is a three-dimensional advection-diffusion model for water-quality parameters and mass transport in water that is used to simulate phytoplankton and zooplankton concentrations. It considers the advection, diffusion and source/sink terms to be separate subroutines and solves the system of equations by a finite-volume, cellcentered, numerical method. The three mentioned processes substantially affect mass transport as well as predictions of the concentrations of different substances in the reservoir and of the time intervals when each process is dominant. Predictions of the phytoplankton and zooplankton concentrations in the reservoir highlight the source/sink effect over other effects. In other words, the concentrations are very sensitive to the source and sink terms. Consequently, their cyclic population variations and growth rates are important factors in the simulation and modeling process. ISSADM is based on four subroutines: velocity adoption, advection, diffusion and sources/sinks. Although the model is capable of determining which of the subroutine processes is dominant, the sources/sinks process dominates concentration predictions in most cases, especially in phytoplankton and zooplankton models. Most of the variations in population and concentration of phytoplankton and zooplankton are due to growth rates, but the model considers the advection and diffusion terms, as well as the sources/sinks to predict concentrations in lakes and reservoirs. Unlike some models, which consider fishes to be a water-quality parameter either separately or along with zooplankton, this model neglects the influence of fishery activities on phytoplankton and zooplankton populations. Therefore, this study does not consider small predator fishes to be a part of the zooplankton group.

\section{Phytoplankton modeling}

Phytoplankton populations significantly influence water-quality parameters because they consume dissolved ions such as nitrogen and phosphorous, where this process is also used for water treatment. Phytoplankton also influence dissolved oxygen concentrations because they produce oxygen during the day and consume it at night. In addition, phytoplankton influence carbon dioxide concentrations and $\mathrm{pH}$ levels according to their type and growing depth. Surface phytoplankton increase water turbidity and, during the blooming season, produce bad smells that should be considered for reservoirs with recreational purposes. Generally, the main phytoplankton species in the reservoir is considered dominant and is used for concentration predictions. The source/sink factors that are considered in the model are listed below (Trancoso et al., 2005):

$$
\text { Sources/Sinks }=\left(\mu_{p h}-r-e_{s}-S-m\right) P h-G
$$


where:

$\mu_{p h}$ : Impure growth rate for phytoplankton $(1 /$ day)

$r$ : Respiration rate for phytoplankton $(1 /$ day $)$

$e_{s}:$ Excretion rate $(1 /$ day)

$S:$ Settling rate $(1 /$ day)

$m$ : Non-predatory mortality rate $(1 /$ day $)$

$P h$ : Phytoplankton concentration $(m g / l)$

$G$ : Grazing source reduction rate $(m g / l / d a y)$

Phytoplankton growth is a function of light and nutrients. The main limiting nutrients are phosphorous, nitrogen, carbon and silica. Other nutrients may also limit the phytoplankton growth, but these have been not considered in this model. Phytoplankton growth is calculated as follows:

$$
\mu_{p h}=\mu_{\max }\left(T_{r e f}\right) f(T) f(L, P, N)
$$

where:

$T:$ Temperature $\left({ }^{\circ} \mathrm{C}\right)$

$f(T)$ : Temperature (function of growth rate)

$\mu_{\max }\left(T_{\text {ref }}\right)$ : Maximum growth rate at reference temperature (1/ day)

$f(L, N, P)$ : Limiting growth function for light and nutrients

\section{$L$ : Light intensity}

The effects of silica and carbon are not considered due to the low concentration of diatoms in the reservoir. Excretion and respiration, the main components of the nutrient cycle, are modeled by a relation that includes all of the wastes from these processes; process waste is the difference between pure and impure phytoplankton growth. Therefore,

$$
r=r\left(T_{r e f}\right) f_{r}(T)
$$

where:

$r$ : Respiration rate plus excretion rate $(1 /$ day $)$

$r\left(T_{\text {ref }}\right)$ : Respiration rate at reference temperature (1/ day)

$f_{r}(T)$ : Temperature function for respiration

All of the phytoplanktonic wastes that are not calculated earlier are considered in the non-predatory mortality rate. This rate considers aging, bacterial cell decay and toxic material availability. The non-predatory mortality rate is calculated as follows:

$$
m=m\left(T_{r e f}\right) f_{m}(T)
$$


where:

$m$ : Non-predatory mortality rate $(1 /$ day)

$m\left(T_{\text {ref }}\right)$ : Non-predatory mortality rate at reference temperature (1/ day)

$f(T)$ : Temperature function for mortality

The settling rate is neglected due to the low turbidity of water in the reservoir.

\section{Zooplankton modeling}

Like phytoplankton, zooplankton have important effects on nutrient cycles and the growth rates of phytoplankton, and are linked to a group of water-quality parameters. Phytoplankton and zooplankton have a cyclic, predator-prey relationship because phytoplankton are a food source for zooplankton, and the fecal materials and corpses of zooplankton are absorbed by phytoplankton. Therefore, populations of phytoplankton and zooplankton are related to each other for long periods of simulation. As in the case of phytoplankton, the main group of zooplankton is generally considered the dominant species in the reservoir and is used for concentration prediction. The source/sink relationship in this model is expressed as follows (Xu et al., 1999; Jayaweera and Asaeda, 1996):

$$
\text { Sources/Sinks }=\left(g_{z}-r_{z}-m_{z}\right) Z-G_{z}
$$

where:

$g_{z}:$ Impure growth rate for zooplankton $(1 /$ day $)$

$r_{z}$ : Respiration rate for zooplankton $(1 /$ day $)$

$m_{z}$ : Non-predatory mortality rate for zooplankton (1/day)

$Z$ : Zooplankton concentration $(m g / l)$

$G_{z}$ : Reduction rate due to predation $(m g / l /$ day $)$

Zooplankton growth is due to reproduction and depends on the content of absorbed nutrients. Some of the absorbed nutrient supply is consumed for reproduction and the residual is accounted for in metabolic losses. The zooplankton growth rate is calculated as follows:

$$
g_{z}=C_{g} E
$$

where:

$g_{z}:$ Impure growth rate $(1 /$ day $)$

$C_{g}$ : Absorption rate (mass of nutrient/ (mass of zooplankton. day))

$E:$ Absorption efficiency

As for phytoplankton, zooplankton respiration is modeled by a general formulation and is a function of temperature. The predatory mortality rate of zooplankton is considered constant, and this rate includes predation by fishes. 


\section{Model application}

The four Chahnimeh reservoirs are man-made, seminatural deep holes that supply water to the cities of Zahedan and Zabol, fisheries, agriculture and recreation. They are located in the southeastern part of Iran, near Afghanistan's border, in Sistan \&Baluchestan provinces. This region receives flood discharges from the Hirmand River. After an eight-year drought, the seasonal discharges of the Hirmand River have recovered in recent years, revitalizing reservoir communities and ecosystems. One of the reservoirs was selected for phytoplankton and zooplankton simulation (Figure 1) because it is located near industrial and agricultural areas and receives wastewater from those sources (Reservoir 1).
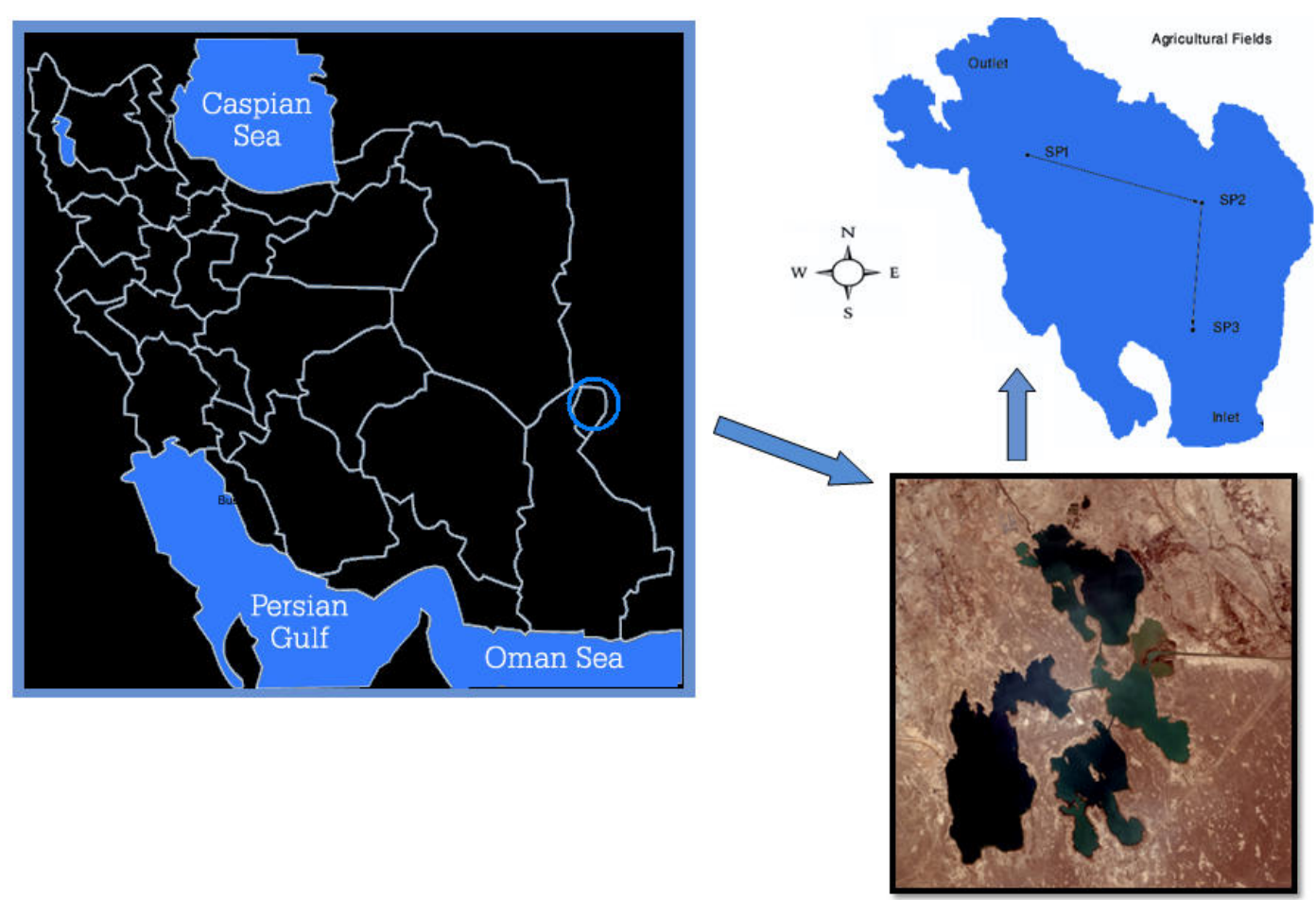

Figure 1. The location of the Chahnimeh reservoirs and sampling points

Modeling was done for a one-year period with seasonal time intervals. Three sampling points in the reservoir, one kilometer apart, were chosen for sampling; their coordinates were recorded by GPS during each sampling event. The authors collected samples at depths of $0,10,20$ and 30 meters from a stationary or slow-moving boat on a sunny day with low wind speed, so that flow turbulences were negligible. Samples were frozen and transported to Zahedan Rural Water \& Wastewater Laboratory for experimentation. The filtering method was used for determining the concentrations of phytoplankton and zooplankton and for seeding to measure their growth rate. Nitrogen and phosphorous concentrations and temperature were considered in calculations of the growth rate of phytoplankton in the reservoir. However, the model utilizes only temperature to calculate the zooplankton growth rate. The different kinetic rates applied for phytoplankton and zooplankton modeling are shown in Table 1. ISSADM was 
developed from a water flow model and incorporates subroutines for the concentrations of different materials, including phytoplankton and zooplankton.

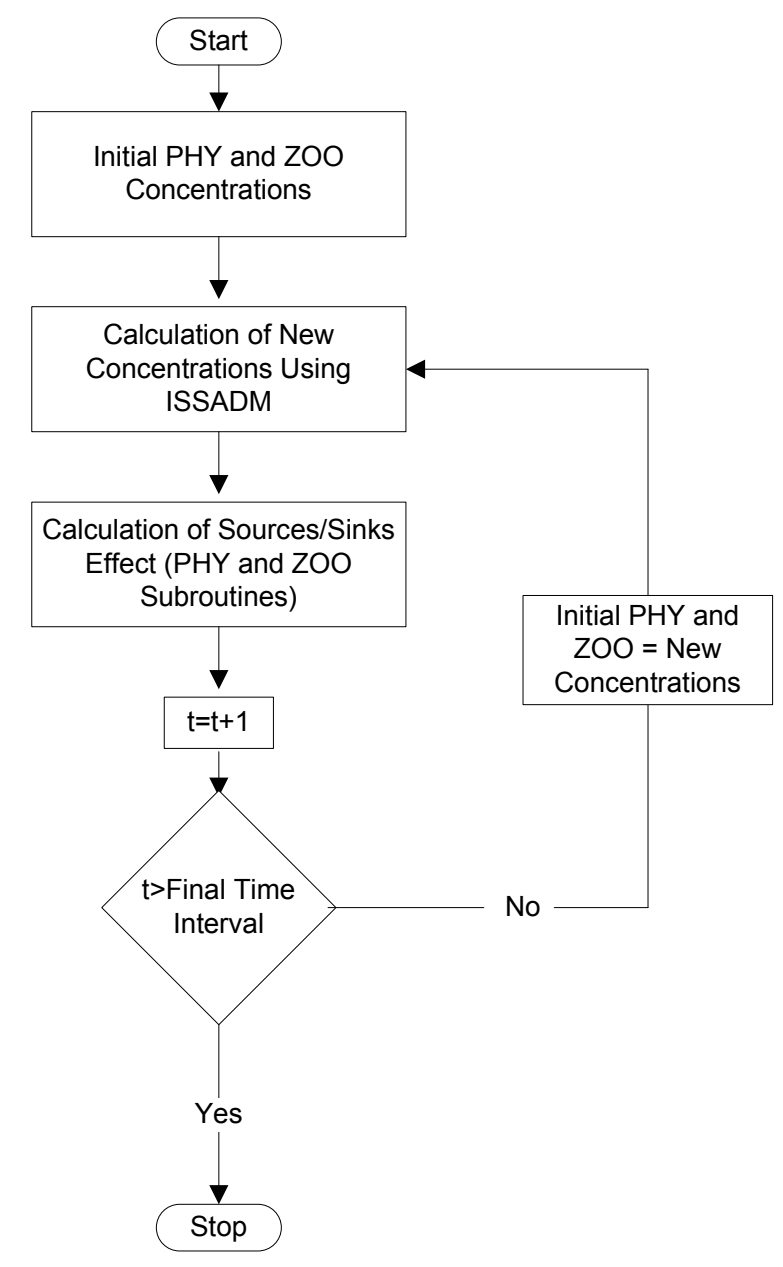

Figure 2. Flowchart of the phytoplankton and zooplankton subroutine

Figure 2 presents a flowchart for the phytoplankton and zooplankton model. The body and subroutines of ISSADM are based on Fortran Visual, which is available in the library of the K. N. Toosi University of Technology and is currently being developed by the authors for modeling heavy metals in lakes and reservoirs.

Table 1. Kinetic rates used in the model for phytoplankton and zooplankton(1/day)

\begin{tabular}{c|c|c|c}
\hline \multicolumn{2}{c|}{ Phytoplankton } & \multicolumn{2}{c}{ Zooplankton } \\
\hline$\mu_{\max }$ & 1.5 & $g_{z}$ & 0.1 \\
$r$ & 0.05 & $r$ & 0.02 \\
$m$ & 0.03 & $m_{z}$ & 0.05 \\
\hline
\end{tabular}




\section{Results and discussion}

In the first step of simulations, the time and space intervals for phytoplankton, zooplankton and water-quality parameter modeling should be specified according to numerical solution limitations. Time intervals are seasonal in ISSADM, and space intervals should be adopted in consideration of the stability of the numerical method. Three sampling points were chosen, each one kilometer apart: SP1, SP2 and SP3. In spring, the phytoplankton concentration at SP1 is $0.161 \mathrm{mg} / \mathrm{l}$ at the surface and 0.02 $\mathrm{mg} / \mathrm{l}$ at the bottom of the reservoir (Figure 3).

\begin{tabular}{lll}
\hline SP1 & SP1 & SP1 \\
\hline
\end{tabular}
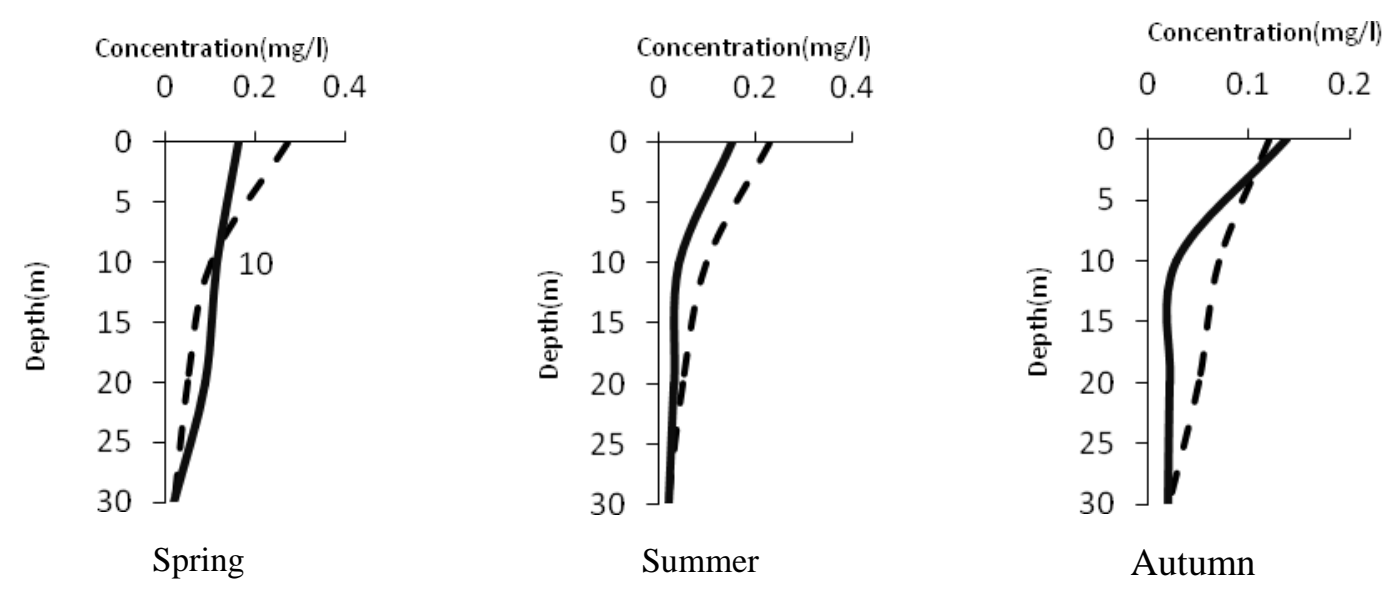

----- Measured

Calculated

Figure 3. Phytoplankton concentration at SP1 in different seasons

In this location, surface-water phytoplankton concentrations are $0.15 \mathrm{mg} / \mathrm{l}$ in summer, $0.13 \mathrm{mg} / \mathrm{l}$ in autumn and $0.10 \mathrm{mg} / \mathrm{l}$ in winter (Figures 3, 4). At SP2 in spring, the concentration of phytoplankton in surface water is $0.17 \mathrm{mg} / \mathrm{l}$ (Figure 4), which decreases slowly to $0.11 \mathrm{mg} / \mathrm{l}$ in winter. At SP3 in spring, the phytoplankton concentration in surface water is $0.16 \mathrm{mg} / \mathrm{l}$, whereas a concentration of $0.10 \mathrm{mg} / \mathrm{l}$ is predicted for winter (Figure 4). Sampling location SP2 is stagnant and has high nitrogen and phosphorous concentrations and effective solar radiation. Therefore, the phytoplankton concentration at SP2 is higher than it is at the other sampling points. The zooplankton concentration at SP1 in spring is $0.093 \mathrm{mg} / \mathrm{l}$ at the surface and $0.02 \mathrm{mg} / \mathrm{l}$ at the bottom (Figure 5). In this location, surface water zooplankton concentrations are $0.11 \mathrm{mg} / \mathrm{l}$ in summer (Figure 5), $0.08 \mathrm{mg} / \mathrm{l}$ in autumn (Figure 5) and $0.13 \mathrm{mg} / \mathrm{l}$ in winter under the same conditions (Figure 6). At SP2, the zooplankton concentration is 0.097 $\mathrm{mg} / \mathrm{l}$ in spring (Figure 6) and $0.066 \mathrm{mg} / \mathrm{l}$ in autumn; at SP3, the surface-water zooplankton concentration is $0.093 \mathrm{mg} / \mathrm{l}$ in spring and $0.063 \mathrm{mg} / \mathrm{l}$ in winter (Figure 6). The concentration of zooplankton is proportional to the growth rate, which is highest in summer. Although the concentrations of phytoplankton and zooplankton are closely 
related, they are also affected by temperature variations in the water column, fishery activities and predators.

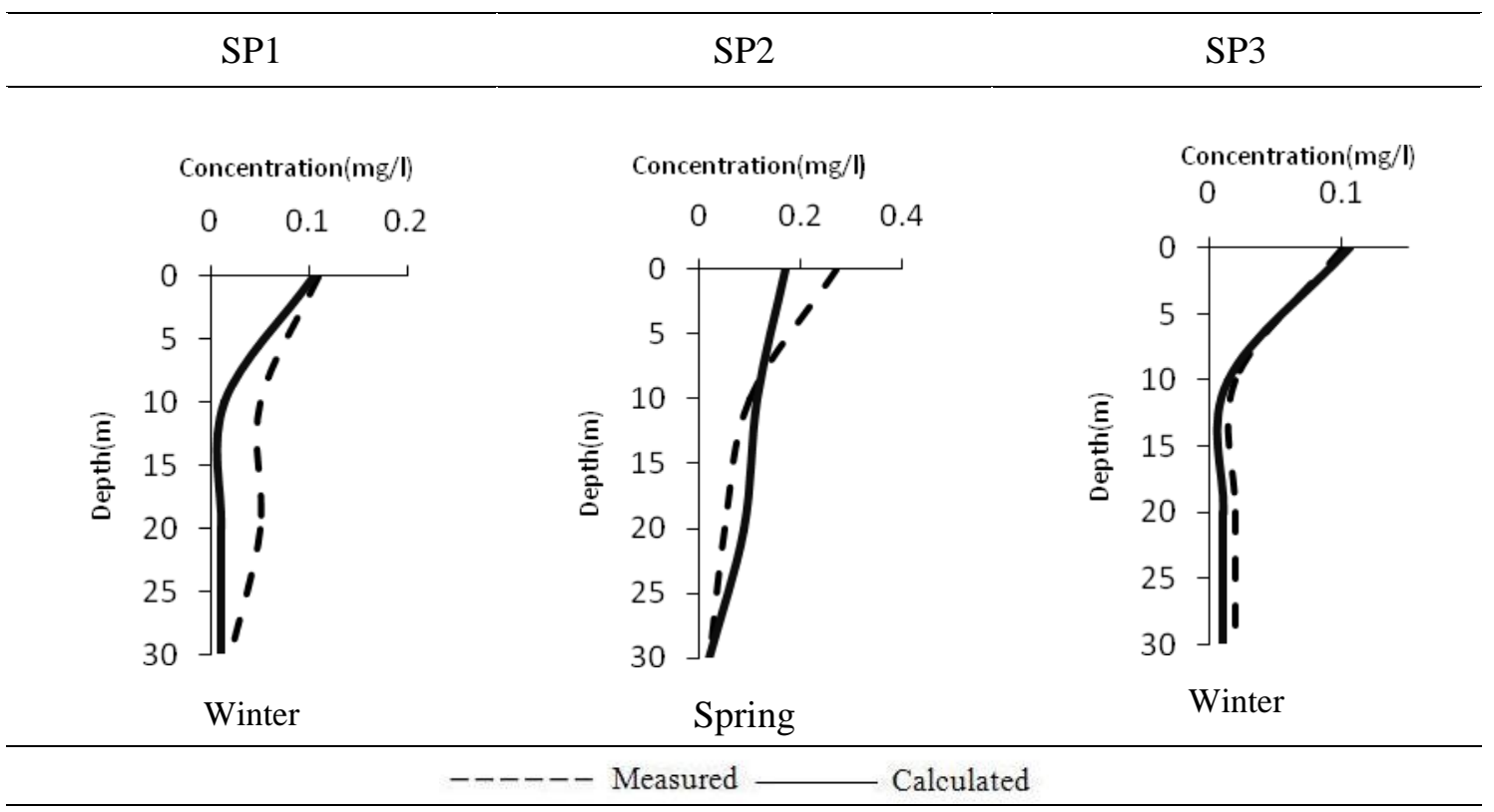

Figure 4. Phytoplankton concentration at different pints and seasons

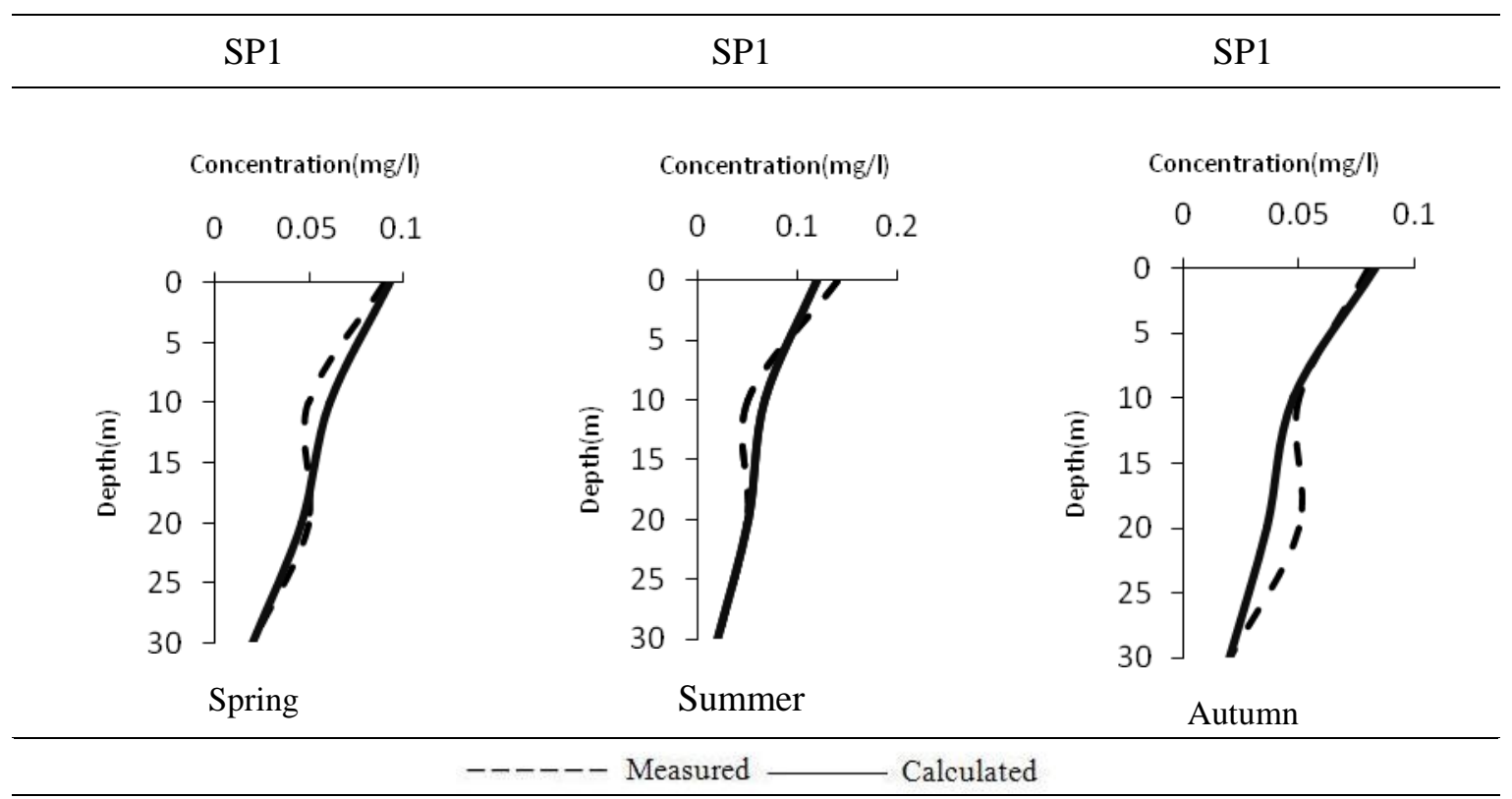

Figure 5. Zooplankton concentration at SP1 in different seasons 


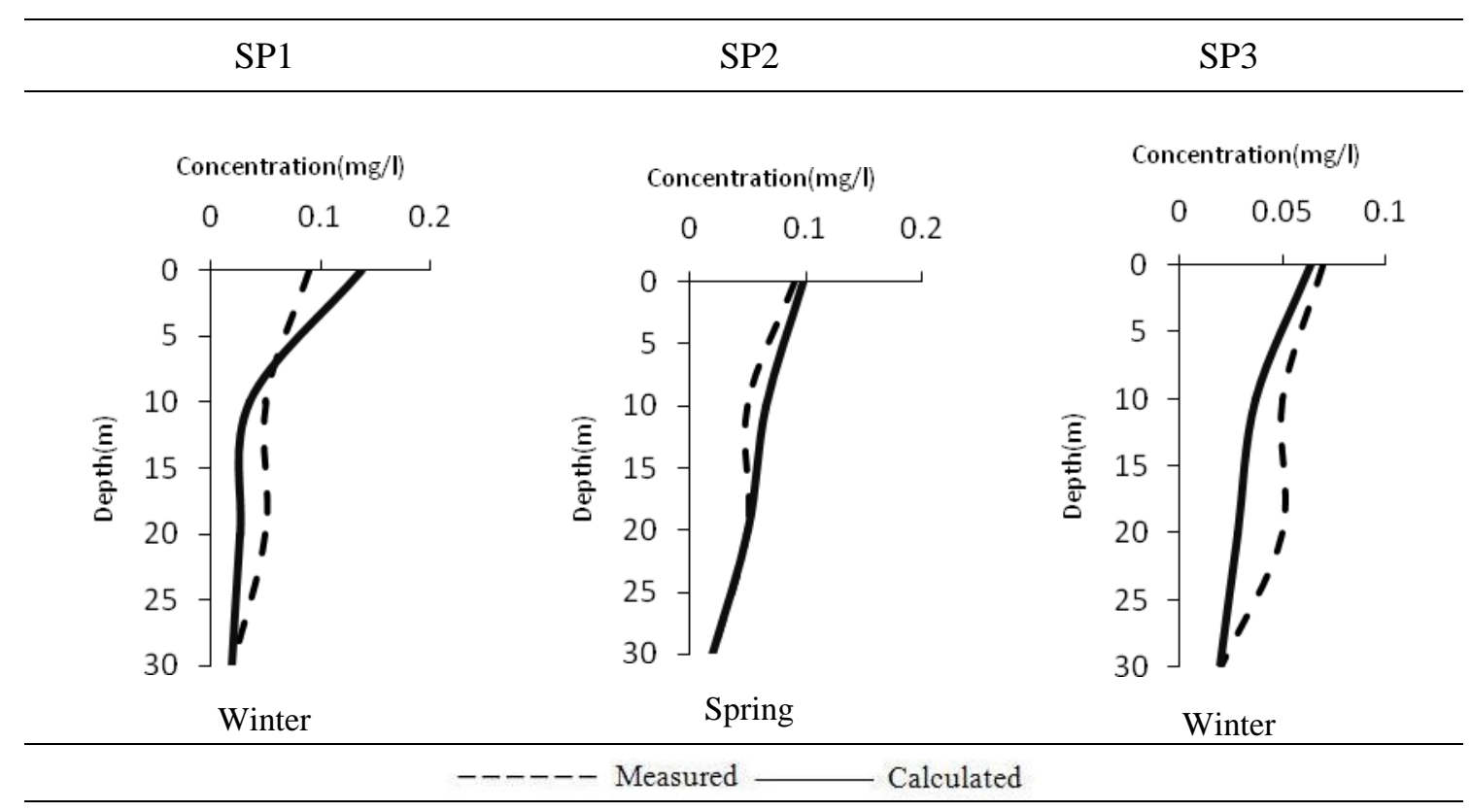

Figure 6. Zooplankton concentration at SP1 in different pints and seasons

Figures 7, 8 present the surface concentrations of phytoplankton and zooplankton in the reservoir.

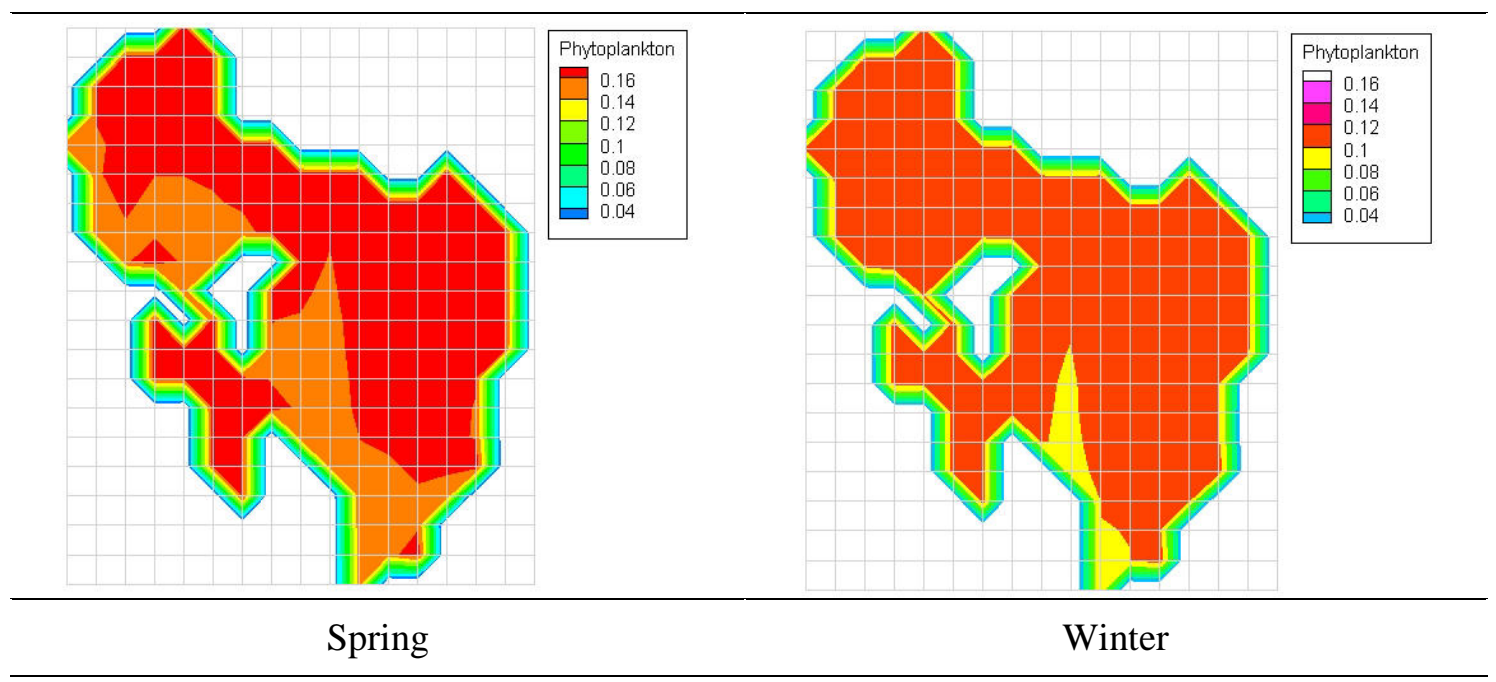

Figure 7. Modeled surface of phytoplankton variation $(\mathrm{mg} / \mathrm{l})$ in the reservoir 


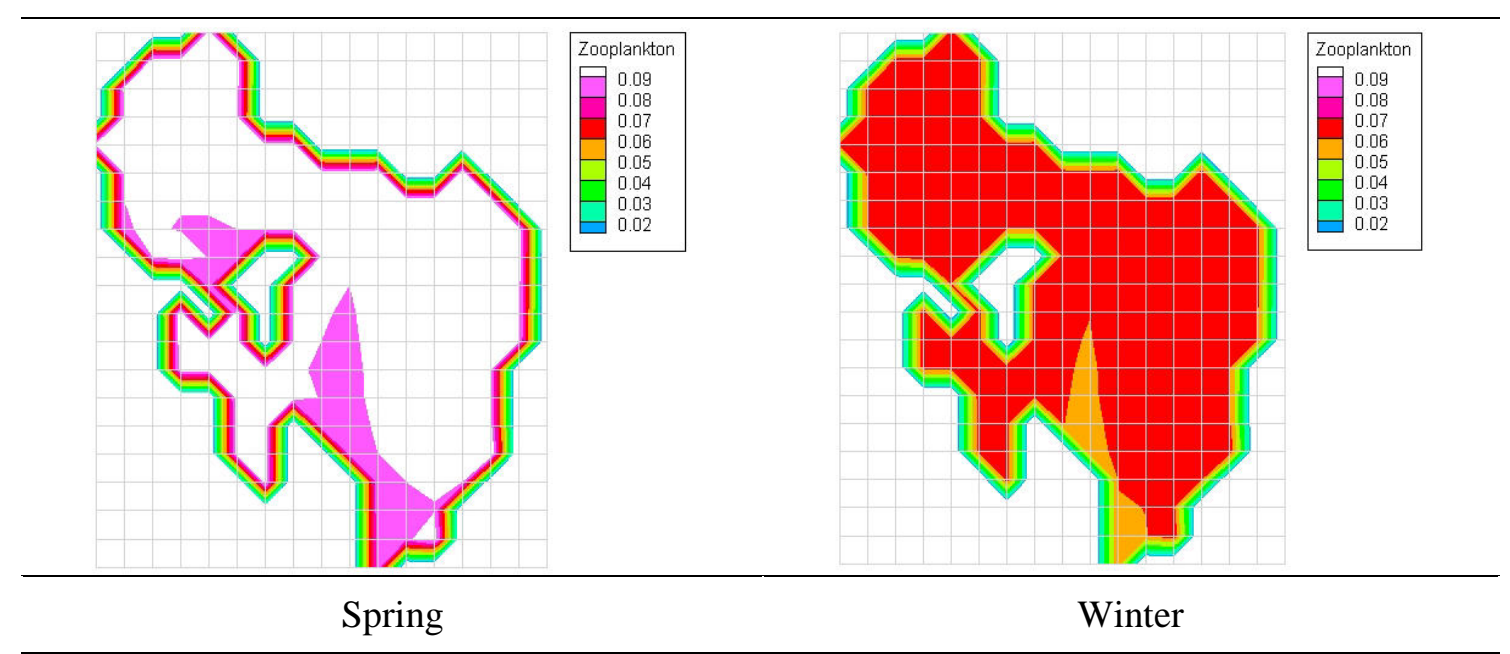

Figure 8. Modeled surface of zooplankton variation ( $\mathrm{mg} / \mathrm{l})$ in the reservoir

\section{Conclusion}

A three-dimensional water-quality model (ISSADM) linked with a hydrodynamic model (Fluent Software) was used to predict phytoplankton and zooplankton concentrations at different locations in Chahnimeh reservoir, a man-made seminatural reservoir near the Afghanistan border in southeastern Iran. Samples were collected from three separate points in the reservoir, and measurements were performed directly by the authors and specialist operators at the Zahedan Water and Wastewater laboratory. Results show that the concentrations of phytoplankton and zooplankton are already low; levels can be further reduced by general water treatment methods.

In this case study the phytoplankton growth is highly nitrogen consumer and the levels of ammonia nitrogen and nitrate should be considered in the model. The phytoplankton concentration is high and decreases in depth. But the decrease rate is different with zooplankton. The high concentration of phytoplankton is calculated in spring. It is happened because high concentrations of nitrogen and phosphorous come to the reservoir by additives of spring agriculture. In most seasons the concentration of zooplankton is low. The zooplankton concentration is not a hazardous parameter for the water now. The rate of decreasing for zooplankton concentration in the reservoir is less than phytoplankton. it is because of zooplankton ability of migration continuously in the water column.

However, to prevent future condition of water pollution, phytoplankton and zooplankton levels in the reservoir deserve attention. Model results were found to agree well with field and experimental data. The parameters listed in Table 1 were obtained through sensitivity analysis and model calibration based on standard error and determination coefficient, and a mean absolute percentage error (MAPE) was then used to evaluate the agreement among data sources. Based on all seasons and sampling points, MAPE values for phytoplankton and zooplankton are $8 \%$ and 5\%, respectively.

Acknowledgement: We give special thanks to Mr. Motadaien, manager of the Sistan \& Baluchistan Rural Water \& Wastewater laboratory, for assisting us with the laboratory analysis of water samples. 


\section{REFERENCES}

[1] Asaeda, T., Trung, V.K., Manatunge, J., Van Bon, T. (2001): Modeling macrophytenutrient-phytoplankton interactions in shallow eutrophic lakes and the evaluation of environmental impacts. - Ecol. Eng. 16: 341-357.

[2] Bruce, L.C., Hamilton, D., Imberger, J., Gal, G., Gophen, M., Zohary, T., Hambright, K.D. (2006): A numerical simulation of the role of zooplankton in $\mathrm{C}, \mathrm{N}$ and $\mathrm{P}$ cycling in lake Kinneret, Israel. - Ecol. Modell 193: 412-436.

[3] Bonnet, M.P., Poulin, M. (2002): Numerical modeling of the planktonic succession in a nutrient-rich reservoir: environmental and physiological factors leading to Microcystis aeruginosa dominance. - Ecol. Modell 156: 93-112.

[4] Burger, D.F., Hamilton, D.P., Pilditch, C.A. (2008). Modeling the relative importance of internal and external nutrient loads on water column nutrient concentrations and phytoplankton biomass in a shallow polymictic lake. - Ecol. Modell 211: 411-423.

[5] Conzonno,V.H, Ulibarrena, J. (2009): Hydrochemistry of Lakes of the Patagonian Province of Tierra del Fuego (Argentina). - Environmental Earth Sciences 59(7): 14311436.

[6] De Dong, J, Ying Zhang,Y., Zhang, S, Shao Wang,Y., Hao Yang, Z., Lin Wu, M. (2009): Identification of temporal and spatial variations of water quality in Sanya Bay, China by three-way principal component analysis. - Environmental Earth Sciences 60(8): 16731682.

[7] Edwards, W.J., Rehmann, C.R., McDonald, E., Culver, D.A. (2005): The impact of a benthic filter feeder: limitations imposed by physical transport of algae to the benthos. Can. J. Fish. Aquat. Sci. 62: 205-214.

[8] Elliott, J.A., Persson, I., Thackeray, S.J., Blenckner, T. (2007): Phytoplankton modeling of lake Erken, Sweden by linking the models PROBE and PROTECH. - Ecol. Modell 202: 421-426.

[9] Elliott, J.A., Thackeray, S.J. (2004): The simulation of phytoplankton in shallow and deep lake using PROTECH. - Ecol Modell. 178: 357-369.

[10] Hedger, R.D., Olsen, N.R.B., Malthus, T.J., Atkinson, P.M. (2002): Coupling remote sensing with computational fluid dynamics modeling to estimate lake chlorophyll-a concentration. - Remote Sensing of Environment 79: 116-122.

[11] Hilmer, I., Van Reenen, P., Imberger, J., Zohary, T. (2008): Phytoplankton patchiness and their role in the modeled productivity of large seasonally stratified lake. - Ecol. Modell. 218: 49-59.

[12] Jayaweera, J., Asaeda, T. (1996): Modeling of biomanipulation in shallow, eutrophic lakes: An application to Lake Bleiswijkse Zoom, the Netherlands. - Ecol Modell.85: 113127.

[13] Komatsu, E., Fukushima, T., Shiraishi, H. (2006): Modeling of P-dynamics and algal growth in a stratified reservoir-Mechanisms of P-cycle in water and interaction between overlying water and sediment. - Ecol Modell. 197: 331-349.

[14] Kuo, J.T., Hiseh, P.H., Jou, W.S. (2008): Lake eutrophication management modeling using dynamic programming. - J. Environ. Manage. 88: 677-687.

[15] Krivtsov, V., Goldspink, C., Sigee, D.C., Bellinger, E.G. (2001): Expansion of the model "Rostherne" for fish and zooplankton: role of top-down effects in modifying the prevailing pattern of ecosystem functioning. - Ecol Modell. 138: 153-171.

[16] Lewis, D.M., Elliott, J.A., Lambert, M.F., Reynolds, C.S. (2002): The simulation of an Australian reservoir using a phytoplankton community model: PROTECH. - Ecol Modell. 150: 107-116.

[17] Li-jiao, Y., Wei-min, Q., Xiao-hui, Z. (2004). Prediction and setup of phytoplankton statistical model of Qiandaohu Lake. - Journal of Zhejiang University Science 5(10): 1206-1210. 
[18] Malve, O., Laine, M., Haario, H., Kirkkala, T., Sarvala, J. (2007): Bayesian modeling of algal mass occurrences using adaptive MCMC methods with a lake water quality model. - Environmental Modeling \& Software 22: 966-977.

[19] Mieleitner, J., Reichert, P. (2008): Modeling functional groups of phytoplankton in three lakes of different tropic state. - Ecol Modell 211: 279-291.

[20] Mirbagheri, S.A., Hashemi Monfared, S.A., Masrorakis, N. (2009): Nutrient transport model in Chahnimeh manmade reservoirs. - WSEAS transactions on environment and development 5(1): 44-54.

[21] Mirbagheri, S.A, Tanji, K.K. (1981): Sedimeny Characterization and transport modeling in Colusa basin drain. Department of land, air and water resources. - University of California.

[22] Nair, M., Jacob, J., Nisha, P.A., Martin, G.D., Srinivas, K., Sheeba, P., Laluraj, C.M., Joseph, T., Balachandran, K.K. (2009): Seasonal variations in the sediment biogenic properties of a tropical mangrove environment, southwest coast of India. - Environmental Earth Sciences 61(1): 27-35.

[23] PhamThi, N.N., Huisman, J., Sommeijer, B.P. (2003): Simulation of 3D Phytoplankton Dynamics: Competition in Light-Limited Environment. - Report Reapport MAS, Modeling Analysis and Simulation.

[24] Rukhovets, L.A., Astrakhantsev, G.P., Menshutkin, V.V., Minina, T.R., Petrova, N.A., Poloskov, V.P. (2003): Development of Lake Ladoga ecosystem models: modeling of the phytoplankton succession in the eutrophication process. - Ecol Modell 165: 49-77.

[25] Skliris, N., Djenidi, S. (2006): Plankton dynamics controlled by hydrodynamic process near a submarine canyon off NW Corsican coast: A numerical modeling study. Continental Shelf Research 26: 1336-1358.

[26] Sterner, R.W., Grover, J.P. (1998): Algal Growth in Warm Temperate Reservoirs: Kinetic Examination of Nitrogen, Temperature, Light, and Other Nutrients. - Wat. Res. 32(12): 3539-3548.

[27] Trancoso, A.R., Saraiva, S., Fernandes, J., Leitao, P., Neves, R. (2005). Modeling macroalgae using a 3D hydrodynamic-ecological model in a shallow, temperate estuary. Ecol Modell 187: 232-246.

[28] Veraszto, Cs., Kiss, K.T., Sipkay, Cs., Gimesi, L., Vadadi-Fulop, Cs., Turei, D. (2010): Long-term dynamic patterns and diversity of phytoplankton communities in a large eutrophic river. - Applied Ecology and Environmental Research 8(4): 329-349.

[29] Walter, M., Recknagel, F., Carpenter, C., Bormans, M. (2001): Predicting eutrophication effects in the Burrinjuck Reservoir (Australia) by means of the deterministic model SALMO and the recurrent neural network model ANNA. - Ecol Modell. 146: 97-113.

[30] Xu, F., Jorgensen, S.E., Taoa, S., Li, B. (1999): Modeling the effects of ecological engineering on ecosystem health of a shallow eutrophic Chinese lake (Lake Chao). - Ecol Modell 117: 239-260.

[31] Zeng, H., Song, L., Yu, Z., Chen, H. (2006): Distribution of phytoplankton in the three Gorge reservoirs during rainy and dry seasons. - Science of the Total Environment 367: 999-1009. 